\title{
TITLE:
}

\section{Impact of cavity extract fans on the thermal and energy performance of existing UK hotel}

\section{AUTHORS}

1. Abdulazeez Rotimi, MSc, BEng

$\mathrm{PhD}$ candidate, Civil Engineering,

University of West London

2. Ali Bahadori-Jahromi,

PhD, MSc, BEng, CEng, FICE

Associate Professor in Civil Engineering,

University of West London.

3. Anastasia Mylona,

PhD, MSc, BEng, CEng, MCIBSE

Research Manager,

The Chartered Institution of Building Services

Engineers (CIBSE).

\section{Paulina Godfrey, PhD}

Director Energy and Environment,

Engineering Operations EMEA, Hilton.

Visiting Researcher,

School of Hospitality and Tourism Management, University of Surrey, UK.

\section{Darren Cook}

Vice President Engineering and

Pre-Opening Operations EMEA, Hilton.

\section{INSTITUTIONS}

University of West London

University of West London

The Chartered Institution of Building Services Engineers (CIBSE)

Hilton

Hilton 


\section{ABSTRACT}

The advantages of Double Skin Facade (DSF) systems, ranging from their aesthetic architectural benefits, acoustic benefits and ability to decrease the heating demand of the internal environment has increased their popularity in Europe since the mid-1980s. However, appropriate consideration must be accorded to its design to ensure their possible advantages are not negated.

This work evaluates how the effect of extraction fans installed in the cavity of the DSF adjoining a central atrium impacts the thermal condition of the atrium and consequently, the overall energy consumption of an existing UK hotel building.

The results of the investigation demonstrated that the DSF extraction fans improve the internal temperature and condition of the adjacent central atrium, especially in the summer. The fans result in a marginal increase in the overall energy consumption when operated throughout the year, hence, the optimum schedule for operation of the extraction fans is during the cooling-dominant period. 


\title{
Impact of cavity extract fans on the thermal and energy performance of existing UK hotel
}

\author{
Abdulazeez Rotimi ${ }^{1}$, Ali Bahadori-Jahromi ${ }^{2}$, Anastasia Mylona ${ }^{3}$, Paulina Godfrey ${ }^{4}$, Darren Cook $^{5}$ \\ ${ }^{1} \mathrm{PhD}$ candidate, University of West London \\ ${ }^{2}$ Associate Professor in Civil Engineering, University of West London \\ ${ }^{3}$ Research manager, The Chartered Institution of Building Services Engineers (CIBSE) \\ ${ }^{4}$ Director Energy and Environment, Engineering Operations EMEA, Hilton; Visiting Researcher \\ at School of Hospitality and Tourism Management University of Surrey, UK \\ ${ }^{5}$ Vice President Engineering and Pre-Opening Operations EMEA, Hilton
}

\subsection{Introduction}

1 The quest for improved energy efficiency and thermal comfort in existing buildings most often

2 involves an all-encompassing approach, incorporating enhanced cost-effective building fabric and

3 retrofit. In the building envelope, façade and especially the glazing has significant impact on the

4 thermal and energy performance of a building (Kaluarachchi et al. 2005; Hee et al. 2015).

5 Currently, the use of highly glazed facades is widespread in high-rise and commercial buildings

6 due to the short application time, low maintenance, lightweight, aesthetic value and durability

7 (Cetiner \& Özkan 2005). However extensive glass curtain wall can result in significant energy

8 consumption due to high solar thermal gains or considerable night heat loss in cold climate

9 (Ghaffarianhoseini et al. 2016).

10 Recent technological advancements have resulted in the availability of high performance, energy

11 efficient window and façade glazing systems that significantly improve thermal performance of

12 glazing. These advancements produce glazing with lower heat loss, less air leakage and warmer

13 window surfaces which enhance comfort and reduce condensation (Ander 2014). Also, modern

14 façade systems have been developed and advanced for greater thermal insulation, shielding from 
15 solar radiation, improved thermal comfort and visual quality (Pasut and De Carli, 2012). The Double Skin Façade (DSF) is one these improved façade systems (Pasut and De Carli, 2012; Kim

17 et al., 2013).

The advantages of DSF systems, ranging from their aesthetic architectural benefits of increased transparency, acoustic benefits and ability to decrease the heating demand of the internal environment while serving as a protection from the external environment has increased their

21 popularity especially in Europe since the mid-1980s (Poirazis 2004; Chou et al. 2009). The main

22 feature of the DSF which provides it with this advantage is the cavity between the external and 23 internal glazed skin that acts as an insulating barrier against the undesirable effects of the external 24 microclimatic condition (Kaluarachchi et al. 2005; Yu et al., 2017). This cavity (air gap) can be naturally or mechanically ventilated, thus the attribute of the cavity space such as its ventilation or 26 shading strategies determines the performance of the DSF (Poirazis 2004; Ghaffarianhoseini et al. 27 2016). The application and role of DSF in a building fabric is complicated as it affects different 28 building parameters that usually interact with each other (such as ventilation, natural lighting, 29 internal air quality, thermal comfort and energy use), hence appropriate consideration must be 30 accorded to its design to ensure their possible advantages are not negated (Poirazis 2004, Yu et al., 31 2017).

32 The DSF system in this case study hotel building adjoins a large central atrium to the east and 33 west, so the aesthetic benefit of multilevel glass façade which permits increased transparency and 34 unimpeded daylighting further enhances the atrium. The application of modern day atrium in 35 commercial builds (especially hotels, shopping malls and offices) became common during the late 36 1950s and early 1960s (Abdullah 2007). The aesthetic value of atria as a space organizer and 37 traditional environmental merits allowing sufficient natural lighting, passive cooling and heating 
are now being exploited in temperate climate building designs in response to high building energy consumption and energy security challenges (Abdullah 2007). Atria have the potential to improve the thermal comfort of occupants by enabling solar radiation, natural heating and cooling which

41 can contribute to reducing lighting, heating and cooling energy demand (Jaberansari \& Elkadi

42 2016). It is a common general assumption that atria automatically reduce the overall energy

43 consumption of a building, but this is a misconception if they are not designed appropriately

44 especially as the thermal behaviour of atrium remains difficult to predict (Abdullah 2007;

45 Aldawoud \& Clark 2008).

The study was necessitated due to the challenge of prevailing high temperature identified in the

47 cavity of the DSF resulting in high temperature in the atrium, thus increasing the cooling demand.

48 Therefore, the option of installing DSF extraction fans was evaluated by this study as an alternative

49 to increasing the chiller capacity which will have considerable impact on the overall energy 50 consumption. It considers the holistic effect of the DSF cavity space ventilation on the total energy

51 consumption. The paper contributes to existing body of knowledge, as most studies in this area

52 use either commercial office building or prototype building as case study or computational fluid 53 dynamic modelling of the DSF cavity alone. Furthermore, it highlights the optimum operational 54 schedule for the extraction fans to ensure increased energy consumption resulting from the 55 installation is neutralized. Moreover, the features of this case study hotel which has a large central 56 atrium and enclosed by DSF to the east and west justifies the need for it to be studied especially 57 as the effect of both features on the energy and thermal performance is difficult to evaluate.

58 The aim of this paper is the evaluation of the effect of extraction fans installed in the east and west 59 cavity of the DSF adjoining a central atrium on the thermal condition of the atrium and 
60 consequently the impact on the overall energy consumption of an existing UK hotel building.

61 Hilton London Heathrow Airport Terminal 4 hotel is used as a case study for this evaluation.

62 The articulated aim is achieved with the following objectives:

- Collection of all necessary data such as (Architectural plans, building fabric makeup, plants/system information and operating energy consumption), site survey is also undertaken to verify collected data.

- Development of holistic hotel model in the dynamic simulation software using the data obtained.

- Estimation of the annual overall energy consumption of the hotel via system modelling of the dynamic simulation software.

- Improvement of the system modelling result by including estimation of unregulated energy use (catering energy use). Subsequently, validation of model results and comparison against actual building operational energy consumption.

- Incorporation of extraction fans in the DSF cavity of the hotel building model and comparison to hotel model without the extraction fans to evaluate their impact on thermal condition of the atrium and overall energy consumption. 


\subsection{Literature Review}

79 Evaluation of existing state of the art indicates that there are considerable and varied amount of

80 literature on the impact of DSF on the energy and thermal performance of building envelopes.

81 Some of these works are presented.

82 Gratia and De Herde, (2004a) and Chou et al., (2009), investigated the effectiveness and behaviour 83 of different glass façade systems. Gratia and De Herde, (2004a) investigated the impact of a south DSF on the thermal behaviour (heating and cooling demand) of a case study office in Belgium 85 using a building simulation software (TAS). Critical periods of the seasons for the DSF corresponding to sunny and cloudy spring, summer, autumn and winter days were analysed. Their

87 case study result illustrated that the application of DSF reduces the winter heating loads and increases the cooling loads during summer. However, their result did not investigate the effect of the DSF on the overall energy consumption. On the other hand, Chou et al., (2009), studied the impact of DSF on the solar heat gain, the envelope thermal transfer value (ETTV) and consequently the building's energy management. This was done using a systemic approach of

92 computer simulation and laboratory experiment and their work considered the impact of 93 influencing parameters like, wall-to-window ratios (WWR), shading coefficients, (SC) and 94 building orientation. Their results indicated that SHGC values of the DSF are considerably higher 95 in the East and West facing façade compared to the North and South facing façade. Additionally, 96 the study indicated that a DSF having WWR of 0.3 reduces the solar heat gain by up $45 \%$ with 97 this potential diminishing as the WWR approaches 0.9.

98 Hoseggen et al., (2008) and Gelesz \& Reith (2015), both evaluated the application of DSF on 99 building energy performance in different climate of Europe with the aid of a building simulation 
software. Hoseggen et al., (2008) investigated the implementation of DSF in Norway (heatingdominant climate); where the DSF was applied to the east façade to optimise energy consumption reduction. The key findings of their work demonstrated that, even though the heating was $20 \%$ higher for a single façade with basic window attributes, the use of improved U-value windows with the single façade produced energy performance closely comparable to that of the DSF solution. Hence, the predicted DSF energy savings are marginal, making the application of the DSF unprofitable. Similarly, Gelesz \& Reith (2015), evaluated the energy performance of a DSF compared to that of a double and triple glazed single façade in Hungary, which is a Central European moderate climate region. The DSF evaluated is characterised by a buffer mode window and a naturally ventilated outdoor air curtain box type window for winter and summer period respectively. The main finding of the study indicated that outdoor air curtain mode DSFs have promising prospect of reducing energy consumption compared to the single skin façade substitutes in Central-Europe, though, the observed energy savings is marginal with a cooling energy saving of $7 \%$.

The works of Gratia and De Herde, (2004b) and Hien et al., (2005), evaluated the effect of DSF and the varied ventilation system on the energy performance of case study office buildings under different climatic conditions, with the aid of building simulation software (TAS). Hien et al., (2005), investigated the impact of DSF ventilation strategies on energy consumption in a tropical humid climate and their result indicated that naturally ventilated DSF could reduce energy consumption and provide improved thermal comfort. Additionally, extraction fans could minimize condensation induced by high humidity. It is worth noting that their work did not consider building orientation. Whereas, Gratia and De Herde (2004b), investigated the energy performance of a DSF with mainly natural ventilation coupled with the DSF orientation and wind speed in a temperate 
123 climate. One of their key findings indicated that night ventilation is more effective than day

124 ventilation as it allows for considerable reduction of building cooling loads. Additionally, the use

125 of shading is relatively more effective in a single glazed building.

126 Fallahi et al., (2010); Parra et al., (2015), both worked on improving the thermal performance and 127 energy efficiency of DSF systems with the use of numerical modeling techniques. Fallahi et al., 128 (2010) presented an approach of introducing thermal mass with the DSF and the energy 129 performance evaluation of its impact on adjacent study room was done using a verified numerical 130 model. Their parametric study result shows that the introduction of thermal mass in the cavity 131 space with mechanical ventilation gives significant energy reduction. Moreover, depending on 132 configuration, up to $26 \%$ summer energy saving and up to $59 \%$ winter energy saving is obtainable 133 relative to conventional DSF without thermal mass. Whereas Parra et al., (2015), used 134 Computational Fluid Dynamics (CFD) to investigate the effectives of Venetian blinds (VB) 135 shading device on improving the performance of DSF. One of their key findings shows that VB 136 can reduce solar heat gain by up to $35 \%$.

\section{3.0 Methodology}

138 The aim of this study is to examine the impact of extraction fans installed in the east and west 139 cavity of the DSF on the thermal performance of enjoining central atrium and overall energy 140 consumption of a case study Hilton hotel building located in the south east of the UK. The 141 evaluation is conducted with the aid of an approved dynamic simulation software.

142 The process that was employed to achieve the stipulated aim with the case study buildings can be 143 categorised into two distinct stages. The first stage involves estimating the energy consumption of 144 the building by developing holistic model reflecting the building fabric, systems and thermal 
145 performance of the actual building. The predicted energy consumption is validated by comparing 146 against actual consumption data. The consumption data are collected from the electronic energy 147 meter reading of the hotel and the case study building is inspected to enable verification of 148 available data such as building fabric data (e.g. walls and windows), occupancy information to 149 ensure simulation assumptions are realistic, building usage to ensure zone grouping is as shown 150 on architectural plan and HVAC system characteristics. The second stage involves the integration 151 of the extraction fans into the model to evaluate their impact.

152 EDSL TAS software version 9.3.3 is employed as the dynamic simulation software to evaluate 153 energy performance for this study. The TAS software, designed by Engineering Development 154 Solutions Limited, is a set of application products with the capability to simulate thermal 155 performance of buildings and their systems which can be translated to energy consumption 156 estimates (Crawley et al, 2008). The software is also approved and fully accredited for the UK 157 building regulation 2013 and demonstrates compliance to various BS EN ISO standards (EDSL, 158 2015). It has a 3D graphic based geometry input interface (3D Modeller) that includes a CAD link 159 and can also perform daylighting calculations (Crawley et al, 2008). The core module is the TAS 160 Building Designer (TBD), it performs dynamic building simulation with integrated natural and 161 forced air flow (Crawley et al, 2008). TAS systems is the component of the software suite which 162 provides plant modelling capabilities to simulate systems such as Heating Ventilation and Air 163 Conditioning (HVAC) systems/control.

164 Weather data used for the simulation must be carefully chosen as it has considerable impact on the 165 result (Rotimi et al., 2017). While engineers can only use the weather data of a year to perform 166 building simulations; the world metrological organisation defines climate as a 30-year period to 167 reduce the effect of natural inter-annual differences in the weather data (Holmes and Hecker 2007). 
168 This poses a question of which year's weather data should be used. Generally, the weather data 169 employed in building simulation models contain hourly records of the core weather variables (like

170 temperature, solar radiation, relative humidity and wind speed) at a location in proximity to the 171 modelled building (Eames 2016). Typically, two different types of weather files are used to run 172 building simulation in the UK; these are the Test Reference Year (TRY) and Design Summer years 173 (DSY) (CIBSE 2017). The weather file of a year that is representative of the weather over certain 174 number of years is referred to as the (TRY) which differs as different countries employs different 175 methods in choosing their TRY (CIBSE 2009a; Amoako-Attah and B-Jahromi, 2016). The weather 176 file comprises of average months chosen from baseline of historical data (Virk \& Eames 2016).

177 The updated CIBSE TRY files are developed using a baseline period of 1984 to 2013 as opposed 178 to the previous TRY using a baseline of 1984 to 2006, therefore, they account for the effect of 179 climate change (Mylona 2017).

\subsection{Building description}

181 The case study building is a six storey hotel constructed in 1990, it is located in Heathrow and due 182 its closeness to the airport, the building is completely sealed for noise abatement. The building 183 consists of two wings situated either side of a central atrium that runs the entire building height 184 from the first floor and the east and west side of the atrium space is enclosed by DSF system. The 185 building is completely air-conditioned apart from the various plant rooms located on the ground 186 floor and sixth floor. The building has a total floor area of $20,881 \mathrm{~m}^{2}$, with the ground floor 187 containing the conference/meeting rooms, back of house offices and gym; the central atrium on 188 the first floor contains the restaurant, bar and reception area; while the 395 guest rooms are housed 189 in the first to fifth floors. 
A 4-pipe FCU supplies treated air to individual bedrooms with the rooftop central Air Handling Unit (AHU) providing additional fresh air. Cooling is provided by three air cooled chillers whilst 13 splits AC systems provides cooling for one of the large conference rooms, back of house and server room. The hotel has a Combined Heat and Power (CHP) unit which provides an onsite electricity generation and is sized to satisfy the domestic hot water demand along with a backup boiler. Since the hotel is in Heathrow, the weather data used for the building energy simulation is the current CIBSE London (TRY) weather file. To aid in the shadow calculation in the 3D Modeller, the latitude, longitude and time zone values of 51.46 degrees North, -0.44 degrees East and UTC +0.0 respectively were inputted to reflect the geographical location parameter of the hotel building. Figure 1 shows the hourly external temperature and global solar radiation of the weather data used for the simulation.

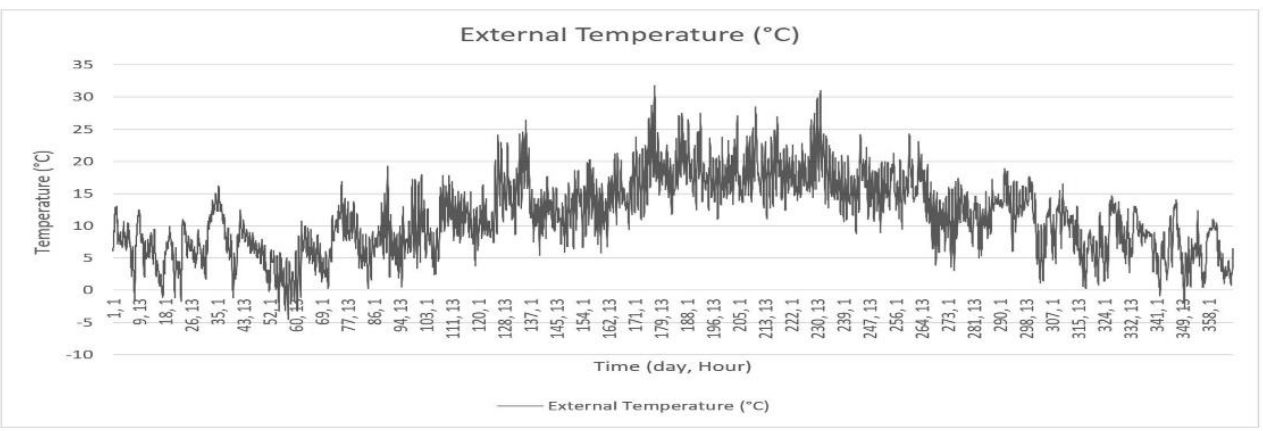

(a) Showing the hourly external air temperature of the CIBSE TRY weather data used for the simulation

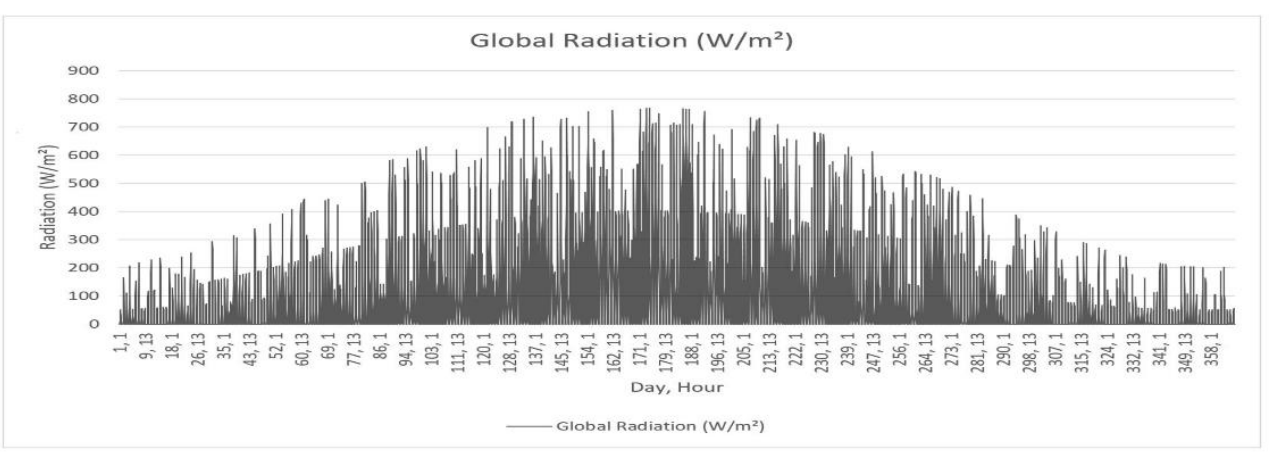

Figure 1: Showing external temperature and global solar radiation of the simulation weather data 


\subsection{Building 3D modelling process}

The 3D modeler component of the TAS software allows data on the building geometry and fabric such as (floors, wall types, windows and doors dimensions etc.) to be inputted. It also enables the grouping of the floor areas into different zones based on their usage, all these data are used to

207 generate the 3D model as close to reality as possible. The data used for the 3D modeling are 208 obtained from the AUTOCAD drawings of the hotel which show plans for individual floors, is 209 presented in figure 2.

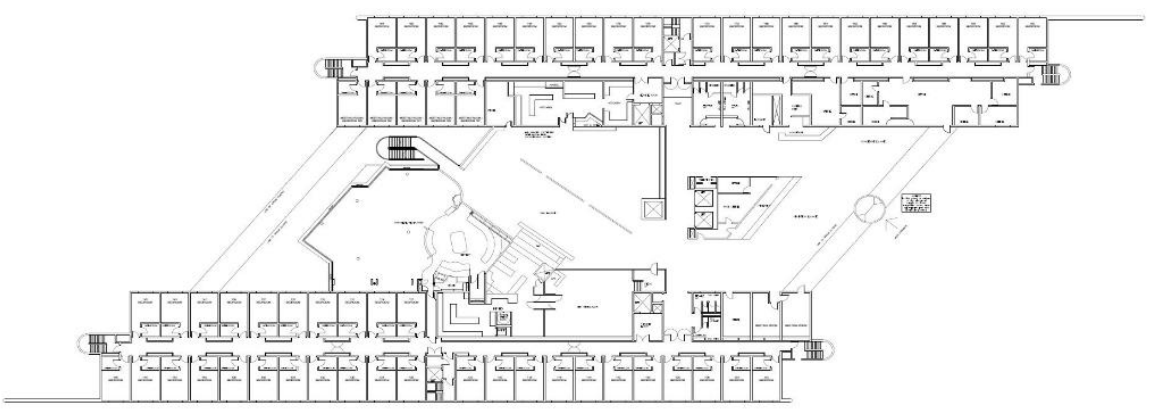

(a) First Floor Plan

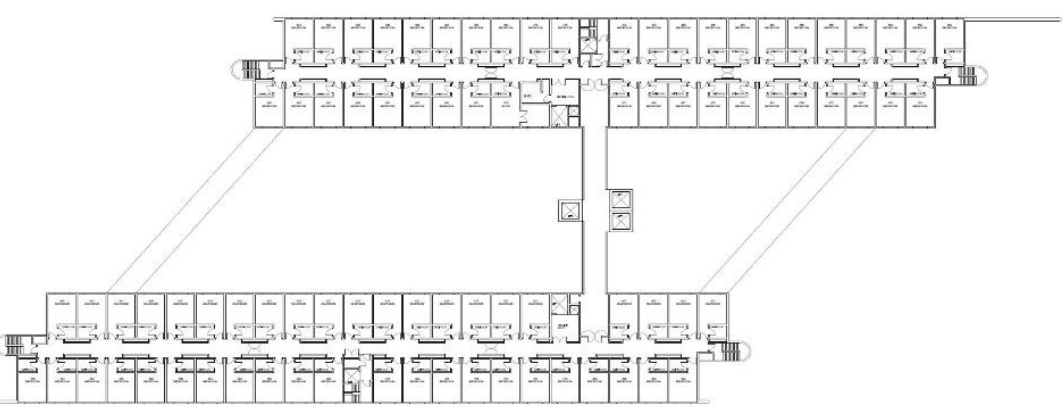

(b) Second Floor - Fifth Floor Plan

211 Figure 2: Architectural plan of the hotel building 


\section{$216 \quad 3.3 \quad$ Thermal simulation process}

217 The thermal simulation of the building is performed by the TBD component of the software which

218 is the core part of the software suite. Appropriate choice of modelling parameters and assumptions

219 are required to execute the building performance simulation.

220 Tables 1 and 2 shows the modelling simulation parameters and assumptions based on the case

221 study building characteristics.

222 Table 1: Modelling and simulation assumptions based on characteristics of the case study building

\section{Building fabric}

Calculated area weighted average $U$-values

Calendar

Air permeability

Average conductance

Alpha values

\begin{tabular}{ll}
\hline Wall & $0.61 \mathrm{~W} / \mathrm{m}^{2} \mathrm{~K}$ \\
\hline Floor & $0.84 \mathrm{~W} / \mathrm{m}^{2} \mathrm{~K}$ \\
\hline Roof & $0.42 \mathrm{~W} / \mathrm{m}^{2} \mathrm{~K}$ \\
\hline Windows & $2.52 \mathrm{~W} / \mathrm{m}^{2} \mathrm{~K}$ \\
\hline Doors & $2.47 \mathrm{~W} / \mathrm{m}^{2} \mathrm{~K}$ \\
\hline High usage entrance & $2.53 \mathrm{~W} / \mathrm{m}^{2} \mathrm{~K}$ \\
door & \\
\hline & $0.98 \mathrm{~W} / \mathrm{m}^{2} \mathrm{~K}$
\end{tabular}

NCM Standard

$5 \mathrm{~m}^{3} /\left(\right.$ h. $\left.^{2}\right)$ at $50 \mathrm{~Pa}$

$14558 \mathrm{~W} / \mathrm{K}$

$6.59 \%$ 
225 Table 2: Modelling and simulation parameters and assumptions

\begin{tabular}{|c|c|c|}
\hline Construction data base & \multicolumn{2}{|c|}{ NCM Construction v5.2.tcd } \\
\hline \multirow[t]{13}{*}{ Occupancy levels; people density; lux level } & Restaurant & 0.2 person $/ \mathrm{m}^{2}, 150$ lux \\
\hline & Changing room & $\begin{array}{l}0.119 \text { person } / \mathrm{m}^{2}, 100 \\
\operatorname{lux}\end{array}$ \\
\hline & Circulation area & $\begin{array}{l}0.115 \text { person } / \mathrm{m}^{2}, 100 \\
\text { lux }\end{array}$ \\
\hline & Bedroom & $\begin{array}{l}0.094 \text { person } / \mathrm{m}^{2}, 100 \\
\text { lux }\end{array}$ \\
\hline & Gym & 0.140 person $/ \mathrm{m}^{2} 150 \operatorname{lux}$ \\
\hline & Food prep/kitchen & $\begin{array}{l}0.108 \text { person } / \mathrm{m}^{2}, 500 \\
\text { lux }\end{array}$ \\
\hline & Hall & $\begin{array}{l}0.183 \text { person } / \mathrm{m}^{2}, \quad 300 \\
\text { lux }\end{array}$ \\
\hline & Office & $\begin{array}{l}0.106 \text { person } / \mathrm{m}^{2}, 400 \\
\text { lux }\end{array}$ \\
\hline & Plant room & 0.11 person $/ \mathrm{m}^{2}, 200 \operatorname{lux}$ \\
\hline & Reception & $\begin{array}{l}0.105 \text { person } / \mathrm{m}^{2}, \quad 200 \\
\text { lux }\end{array}$ \\
\hline & Store & 0.11 person $/ \mathrm{m}^{2}, 50 \operatorname{lux}$ \\
\hline & Swimming pool area & $\begin{array}{l}0.140 \text { person } / \mathrm{m}^{2}, \quad 300 \\
\text { lux }\end{array}$ \\
\hline & Toilet & $\begin{array}{l}0.118 \text { person } / \mathrm{m}^{2}, \quad 200 \\
\text { lux }\end{array}$ \\
\hline
\end{tabular}

Fuel source

Natural gas

$\mathrm{CO}_{2}$ factor -0.198 $\mathrm{Kg} / \mathrm{kWh}$

Grid electricity $\quad \mathrm{CO}_{2}$ factor -0.4121

$\mathrm{Kg} / \mathrm{kWh}$

\section{$227 \quad 3.4 \quad$ Plant/systems modelling}

228 TAS systems module of the software suite enables the thermal simulation result file referred to as

229 (TSD file) to be directly attached to it. The systems module uses the TSD file to complete the 230 simulation of the building's plants consisting of (heating \& cooling circuits, Air Handling Units, 231 and energy sources) and produce energy performance results. However, the estimate does not 
232 account for unregulated energy use such as catering which can be significant in a hotel building

233 and is therefore estimated in this work to augment the TAS systems result.

234 Figure 3 presents the summary of the case study process.

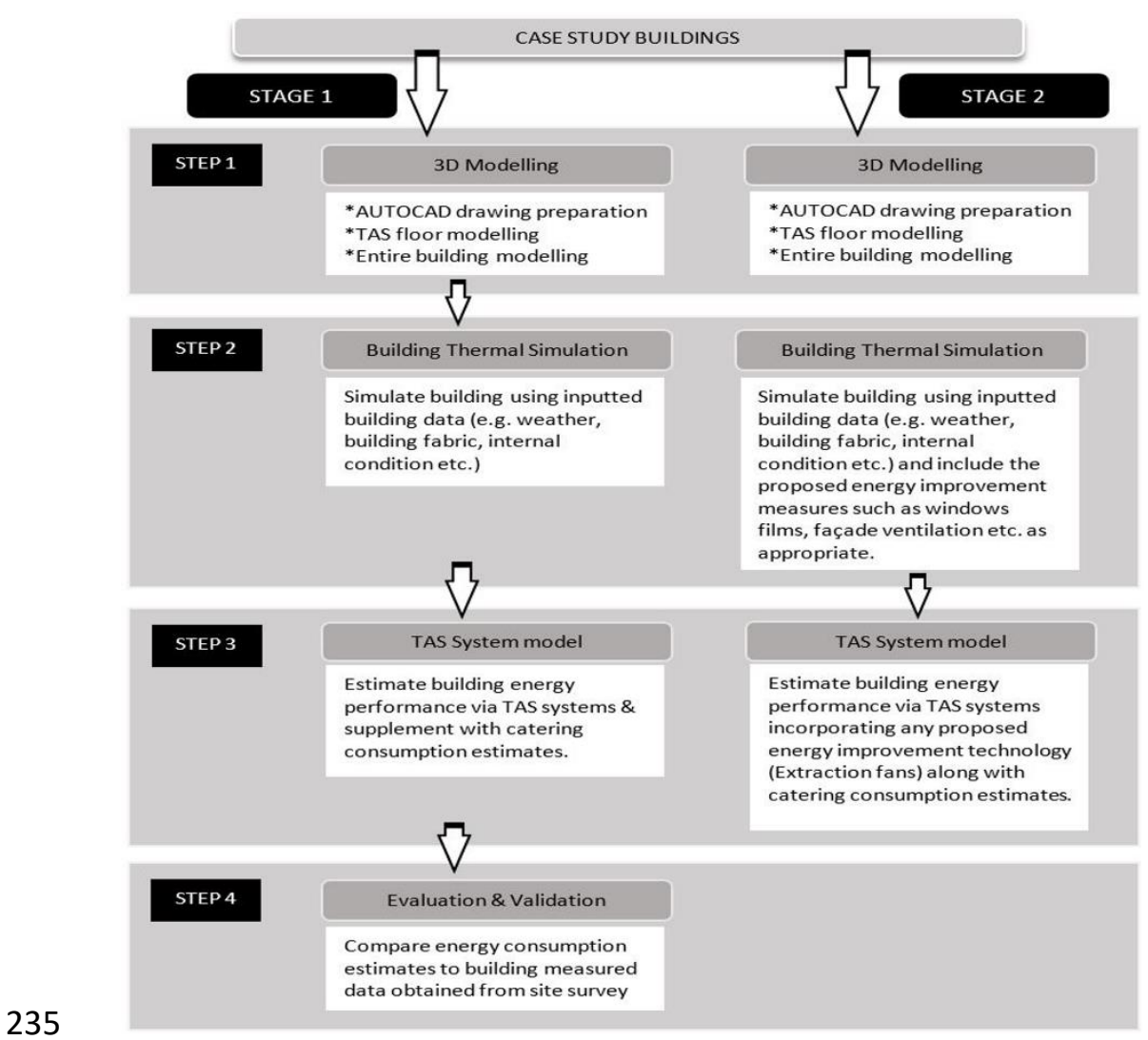

Figure 3: Summary of case study process 


\subsection{Results and Discussion of Result}

245 The result and discussion for the case study hotel building is presented in this section. Figure 4, 246 presents the result of the $3 \mathrm{~d}$ modelling process.

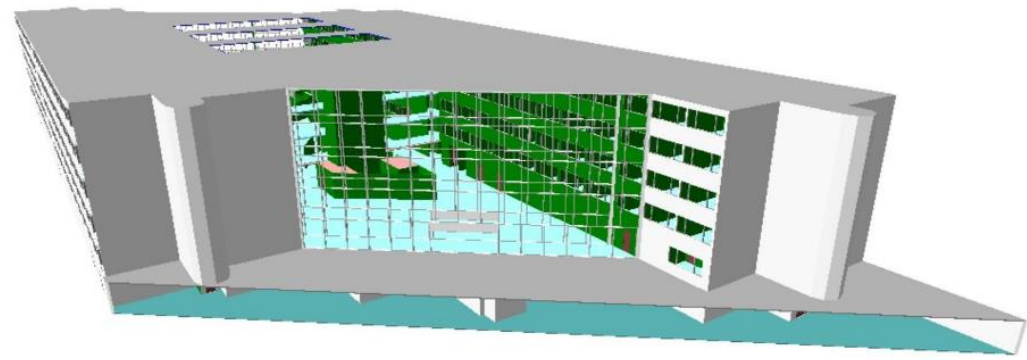

(a) Front view

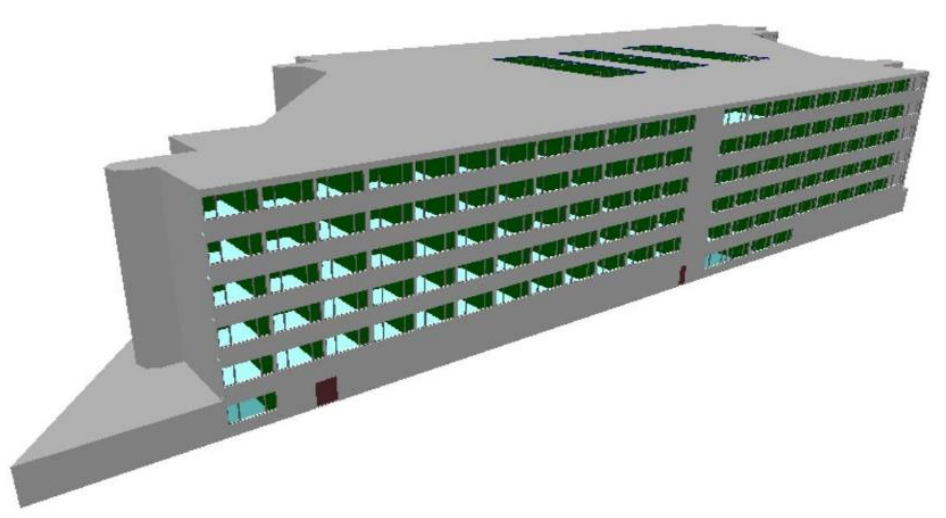

Figure 4: 3d modelling results

249 The TAS TBD component of the software is populated appropriately and simulated to reflect the

250 characteristics of the building operating without extraction fans installed in the east and west facing

251 DSF. The simulated TBD file is attached to the system and plant modeling component of the

252 software to obtain energy performance results of the building. Typical results which includes

253 reports of annual energy consumption, monthly energy consumption simulation of the case study

254 hotel building is presented. The energy consumption estimate comprises of heating, cooling,

255 auxiliary, lighting and equipment energy use. 


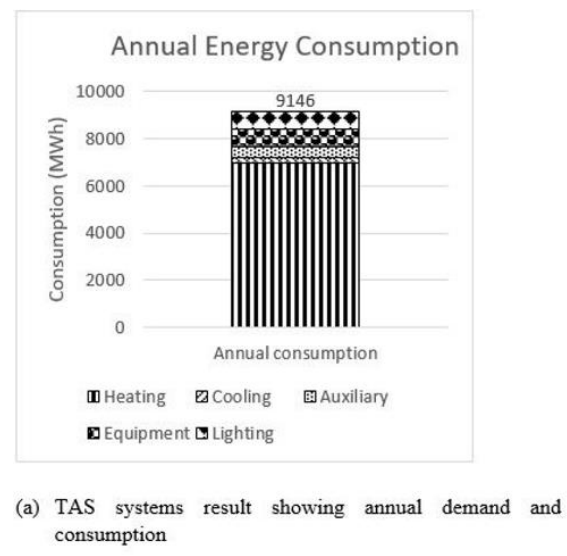

256

257

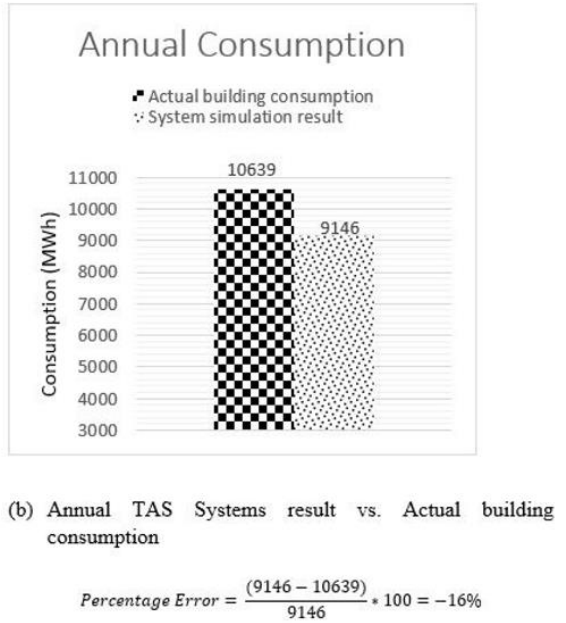

Figure 5: Showing energy performance result from plant/system simulation

Figure 5(a) illustrates the annual energy consumption for the building obtained via plant/system simulation. It shows the breakdown of the energy consumption result which comprises: heating, cooling, auxiliary, equipment and lighting. Auxiliary energy is the energy used by controls, pumps, and fans for the HVAC systems and the heating includes both space heating and DHW. In computing the heating and cooling demands, there is a standard allowance for small power heat gains, which is from the equipment energy use. From figures 5(b) it is observed that the total energy consumption predicted via the plant/system modelling is relatively lower compared to the actual building consumption data with a percentage error of $-16 \%$ representing an underestimation. Even though the building fabric and internal condition parameter was judiciously selected to ensure building simulation replicate real build operation, this discrepancy is still evident. The discrepancy is largely attributed to the fact that the estimated energy does not account for some energy use, referred to as (unregulated energy use) such as catering services which can be significant in a hotel building. Additionally, deviation due to local microclimate of the building's location and the standard weather data used for building energy simulation can result in discrepancy between predicted and actual energy consumption. 
273 Energy use for catering services is estimated and used to augment the result. This is undertaken to

274 further enhance the result and make the baseline model much more acceptable for evaluation of

275 the impact of the extraction fans on the thermal condition of the adjoining atrium and the overall

276 energy consumption of the building. Since simple and reliable calculation estimates for catering

277 energy use are difficult to come by, the catering energy use is estimated using the CIBSE TM 54

278 benchmark for commercial kitchen (CIBSE, 2009b).

279 The operational energy benchmark of $(2.54 \mathrm{kWh}$ for fuel and $1.46 \mathrm{kWh}$ for electricity) for a good

280 practice business/holiday hotel building type was used along with the hotel data of number of

281 meals served. Figure 6 presents the results for systems simulation plus catering energy

282 consumption estimate.

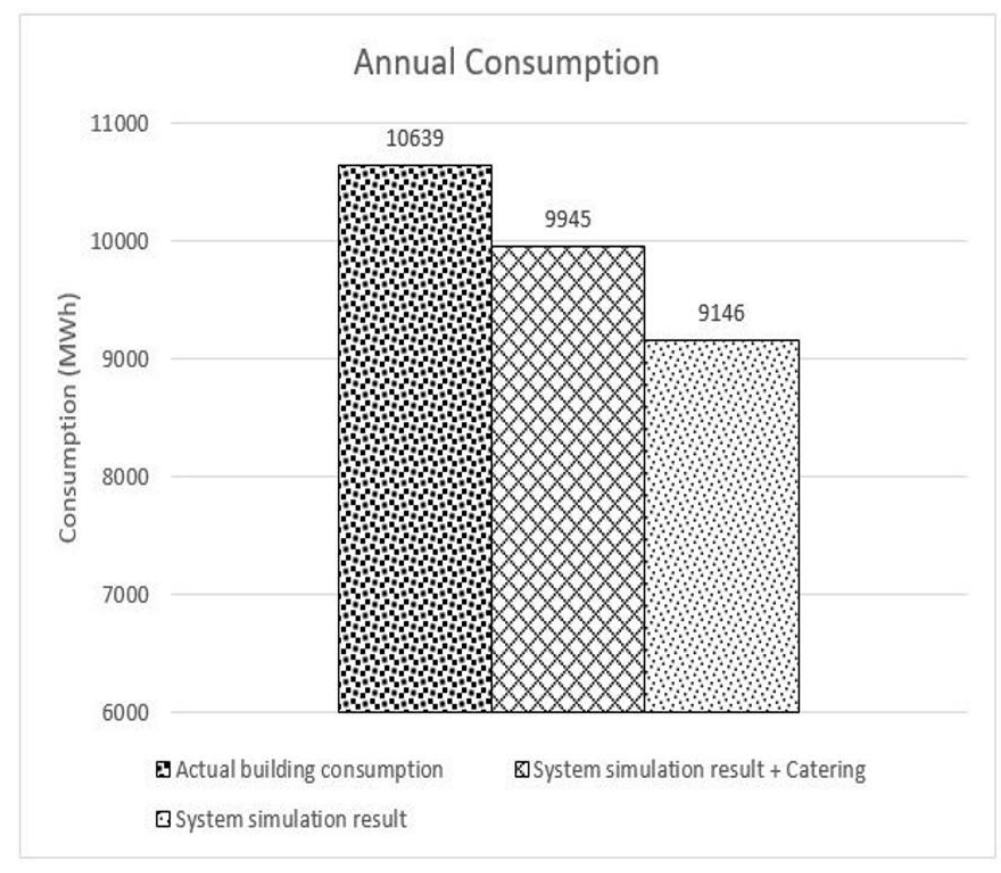

$$
\text { Percentage Error }=\frac{(9945-10639)}{9945} * 100=-7 \%
$$

284 Figure 6: Annual systems simulation result + Catering energy use vs. Actual building consumption 
285 It can be seen from figure 6 that the system simulation result supplemented with catering energy

286 use estimate still underestimates the overall annual energy consumption compared to actual

287 building data. However, the result of the overall energy consumption estimate is significantly

288 improved giving an underestimation of $7 \%$.

289 The next phase of the analysis involves the simulation of the case study building with extraction

290 fans installed in the east and west facing DSF adjoining the central atrium. The result and analysis

291 of this simulation are presented in figures 7 to 12.

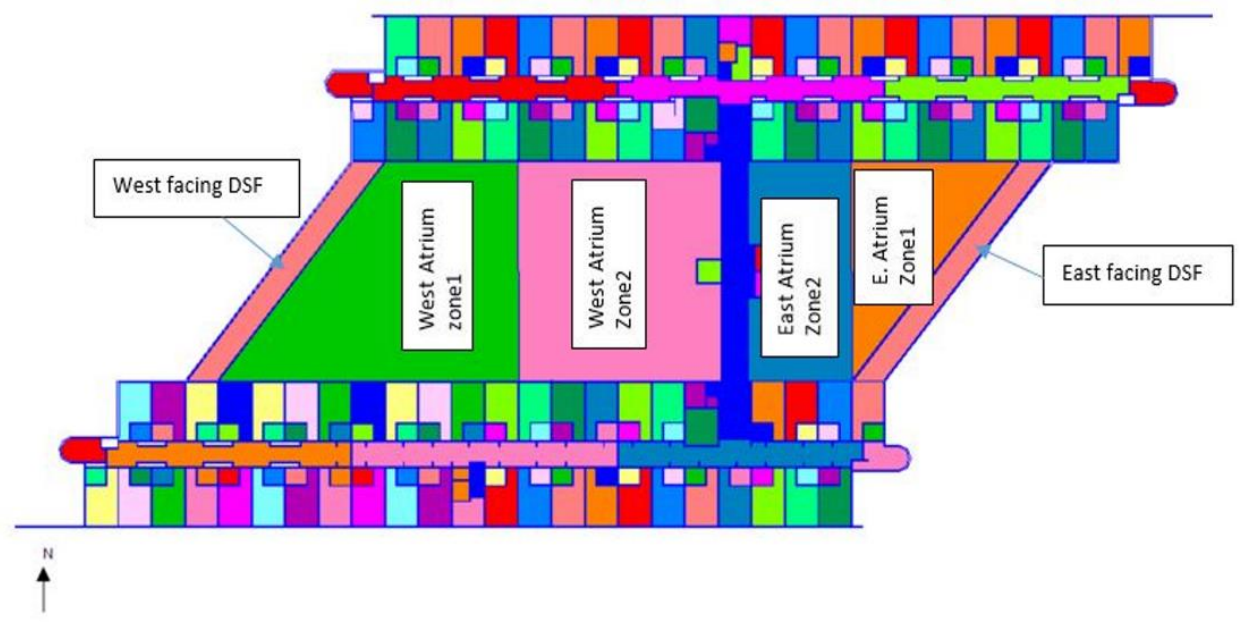

293 Figure 7: Showing zoning of atrium and adjoining double skin façade.

294 Figure 7 shows the different zoning of the central atrium space and façade along with their 295 respective orientation (i.e. west or east). The central atrium space to the east and west are sub296 divided in zone $1 \& 2$ with a null line because of the size of the space. The division with null lines 297 does not act as a wall in the simulation, it is only employed to divide large spaces into smaller 298 units to facilitate the analysis process and improve the output. 
299 The internal condition applied to the west and east DSF façade cavity space is 'unoccupied unconditioned' which implies that no cooling or heating is used in that space. Whereas, the main

301 atrium space is simulated as internal circulation space where heating or cooling is applied.

302 The simulation results of the baseline model with unventilated DSF cavity showing the 303 temperature difference between the east \& west façade space and the main central atrium is 304 presented in figure 8 . The temperature result analysis is presented to provide an understanding of 305 the prevailing temperature in the façade cavity and its influence on the operating temperature of 306 the atrium space.

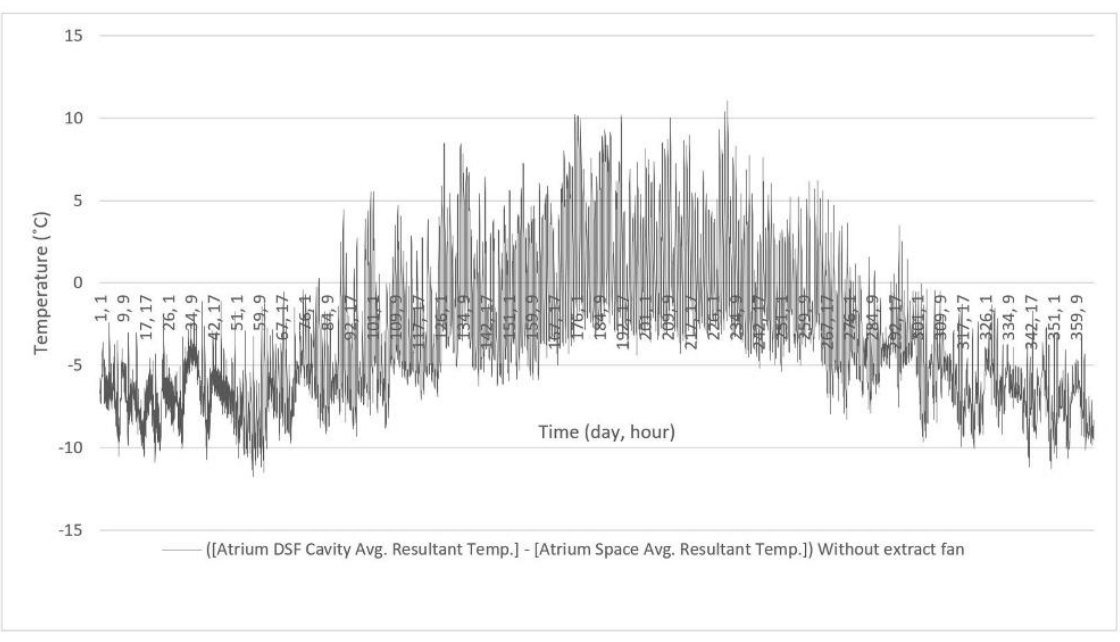

308 Figure 8: Showing resultant temperature difference between the DSF cavity and central atrium 309 (without extract fans)

310 Brief description of the line on the graph presented in figure 8 is given to aid in the comprehension 311 of the subsequent critical analysis of the figures.

312 [Atrium DSF cavity avg. resultant temp. - Atrium space avg. resultant temp. $\left.\left({ }^{\circ} \mathrm{C}\right)\right]$ line on the 313 graph is showing the plot of the value of (atrium DSF average resultant temperature) subtracted 314 from (atrium space average resultant temperature). Hence, a negative (-) value implies that the 
315 temperature of the (atrium DSF resultant temperature) is less than that of the (atrium space average

316 resultant temperature) and a positive (+) value implies the opposite.

317 It can be observed from figure 8, that the prevailing resultant temperature in both the east and west

318 DSF cavity is largely significantly higher during the summer period than the prevailing resultant

319 temperature in the adjoining atrium space. Also, the DSF cavity temperature is generally lower

320 than that observed in the atrium space during the winter season. From critical analysis of the figure,

321 it can be observed that the temperature difference between the atrium's DSF façade cavity and the

322 central atrium is quite significant especially at the peak of the cooling and heating periods.

323 Temperature difference of between $10^{\circ} \mathrm{C}$ to $11{ }^{\circ} \mathrm{C}$ is observed at the peak of the cooling period in

324 June and July. Similar trend is observed around the peak of the heating period, between October

325 and February where a temperature difference of $-10^{\circ} \mathrm{C}$ to $-12{ }^{\circ} \mathrm{C}$ is obtained. The considerable

326 temperature difference observed from the simulation can significantly affect the heating and

327 cooling loads of the central atrium space especially in warmer weather scenarios, leading to

328 increased risk of overheating and adverse effect on the thermal comfort of the atrium space. 

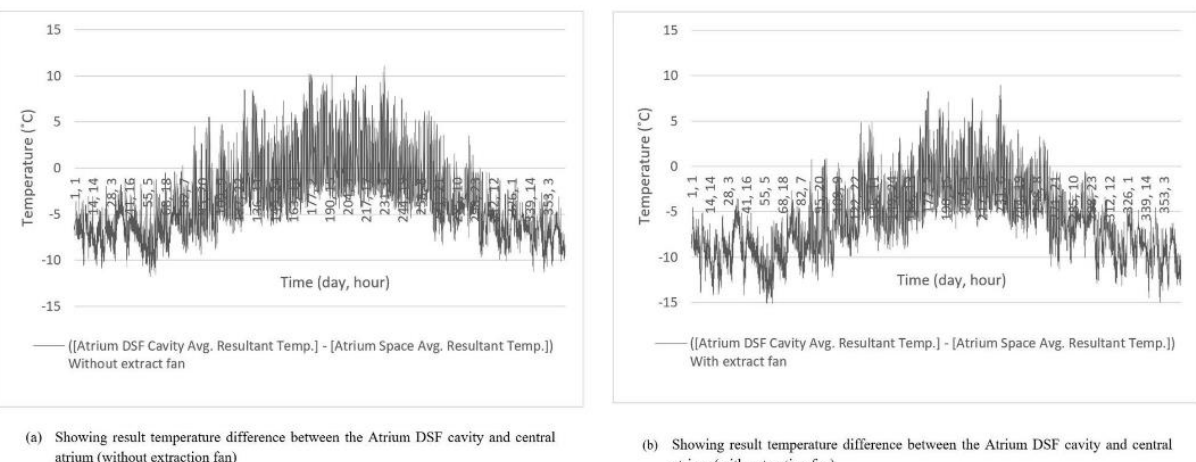

(a) Showing result temperature difference between the Atrium DSF cavity and cent 1

(b) Showing result temperature difference between the Atrium DSF cavity and central trium (with extraction fan)

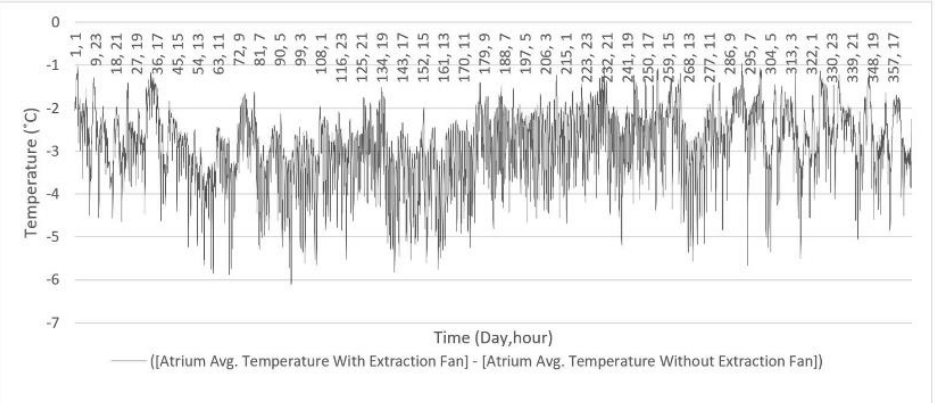

Figure 9: Showing resultant temperature result in the DSF cavity and central atrium (with and without extraction fan)

332 From figure 9(a) and (b) which presents the comparison of resultant temperature difference 333 between the DSF cavity and the central atrium for the model simulation with and without 334 extraction fan. The figure demonstrates that the installation of the extraction fans considerably 335 reduces the temperature difference between the east and west DSF and the adjoining central atrium 336 across the year. This helps to enhance the internal temperature of the central atrium especially 337 during the summer period, thus reducing the risk of overheating and cooling demand. However, 338 the reduced temperature difference is not favourable during the peak of the heating season as the 339 warmer temperature in the DSF cavity is needed to reduce heating load. Furthermore, from figure 3409 (c), the negative values (-) result from the subtraction of atrium resultant temperature with 
341 extraction fan from the atrium resultant temperature without an extraction in the DSF cavity shows

342 that the extraction fan generally reduces the atrium resultant temperature.

343 The impact of the extraction fans on the overall energy consumption of the hotel building is 344 presented in figures 10 to 12.

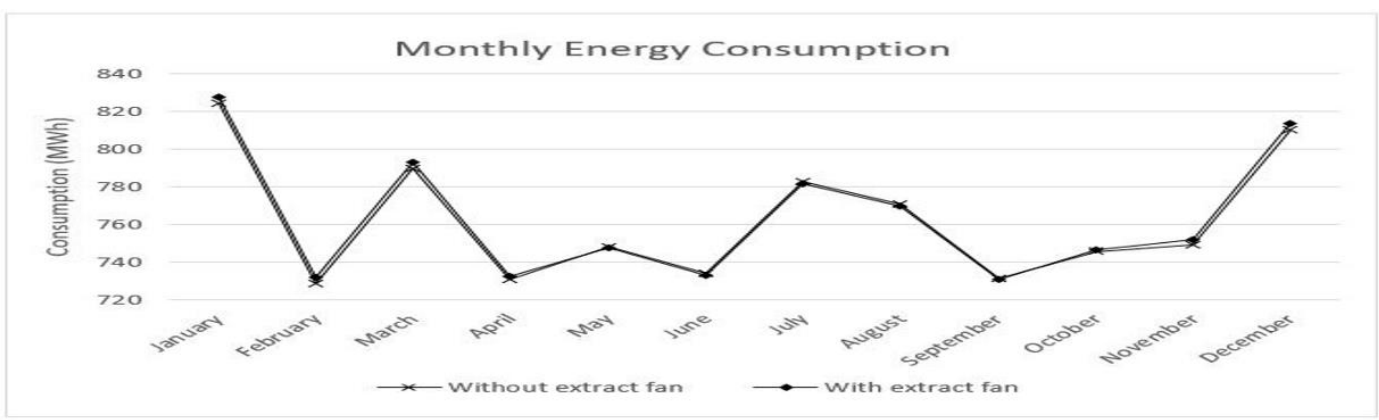

(a) Monthly overall energy consumption result

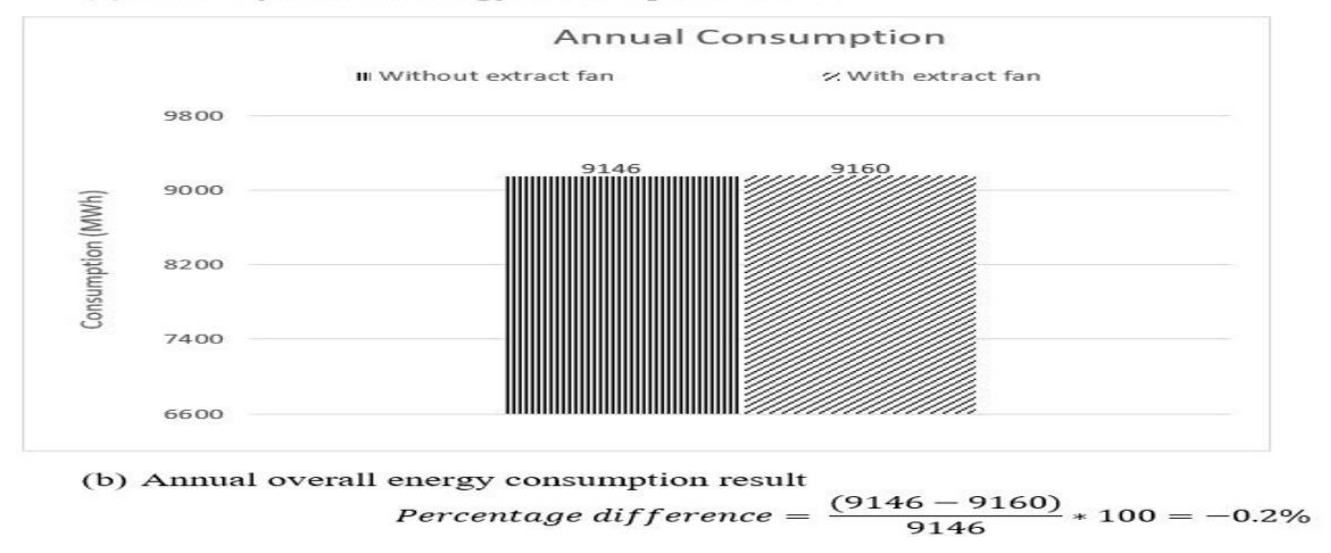

346 Figure 10: Overall energy consumption result for simulation with and without extract fan

347 Figure 10 illustrates the overall energy consumption result for the simulation evaluating the impact 348 of the extraction fans in the DSF cavity adjoining the central atrium compared to the baseline 349 model without extraction fans. From Figure 10(a) and (b), it can be observed that the operation of 350 the extraction fan during throughout the year results in a $0.2 \%$ marginal increase in the overall 351 energy consumption when compared to the energy simulation result of the model without the 352 extraction fan. Though the impact of the extraction fans on the overall energy consumption is not 353 substantial, it is insightful to analyse the effect of the fans on the components of the energy 
354 consumption that they have direct influence on. This is helpful to deduce the optimum operation 355 schedule for the extraction fans. Therefore, the energy consumption result for heating and cooling 356 are presented figure 11.

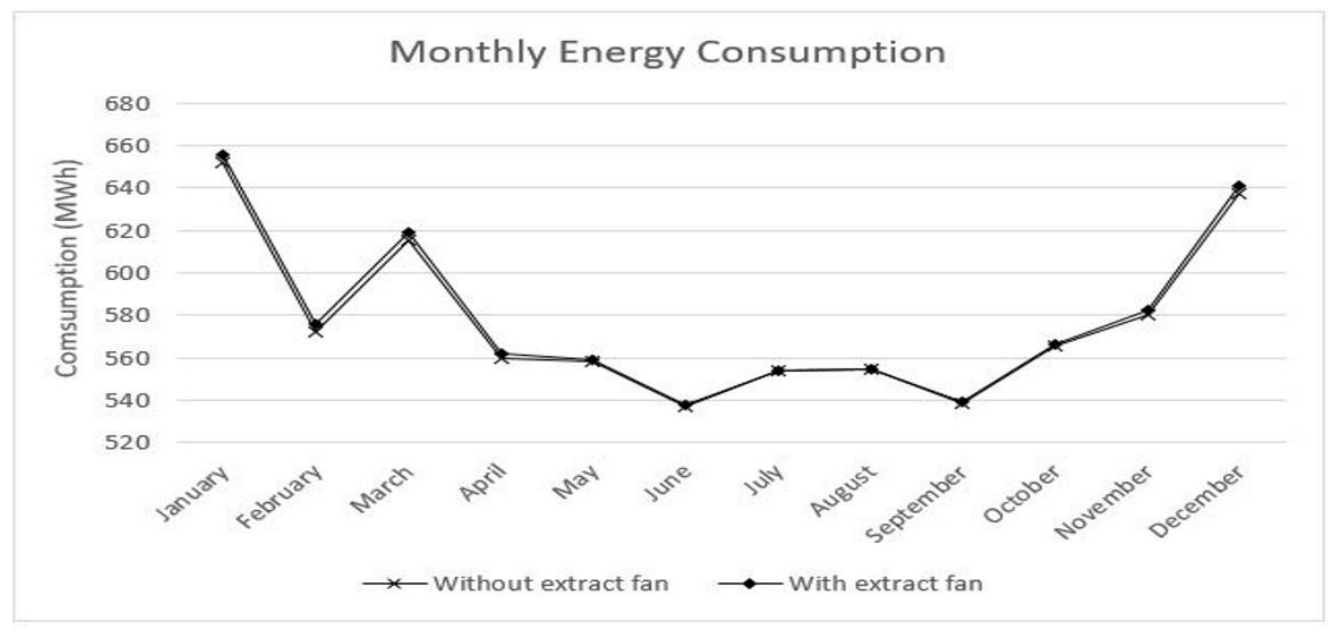

(a) Heating energy consumption

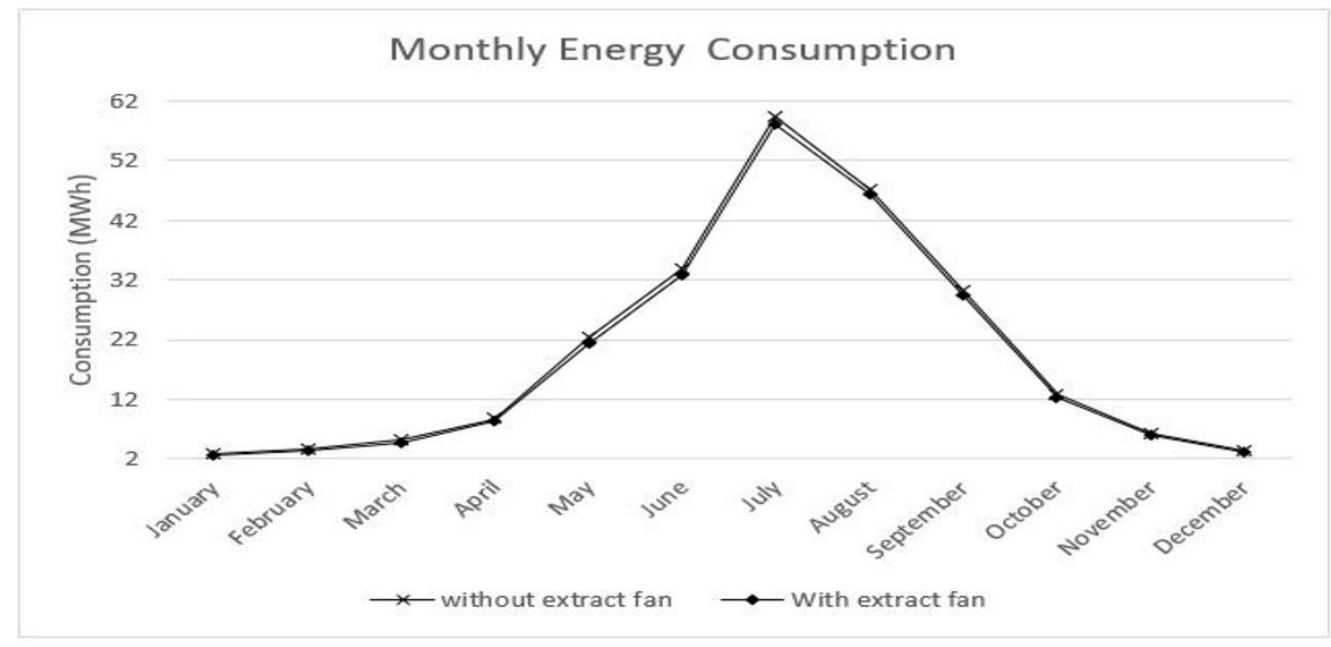

(b) Cooling energy consumption result

358 Figure 11: Impact of DSF cavity extraction fan on the heating and cooling energy consumption

359 From Figure 11(a), showing the heating energy consumption, it reveals that there is no energy 360 consumption savings accruing from the operation of the extraction fans in the DSF cavity. This is 361 because the heat gain from solar radiation in the façade is required during the heating season to 
362 reduce the building's heating load. Moreover, the figure shows that there is a slight increase in

363 heating energy consumption in October to April with the DSF extraction fans in operation.

364 However, from Figure 11(b) illustrating the cooling energy consumption, it is observed that the 365 cooling energy consumption savings accruing from the operation of extraction fans in the DSF 366 cavity is marginal. The maximum cooling energy consumption savings is observed in June to 367 August during the summer period. Therefore, from analysis of the case study result, the optimum 368 schedule of the extraction fan is during the cooling dominant period from May to September. 369 Figure 12 demonstrates this by comparing the overall energy consumption results of the building 370 without the extract, with the extract fan in operation all year round and with the extract fan 371 operating only during the summer period.

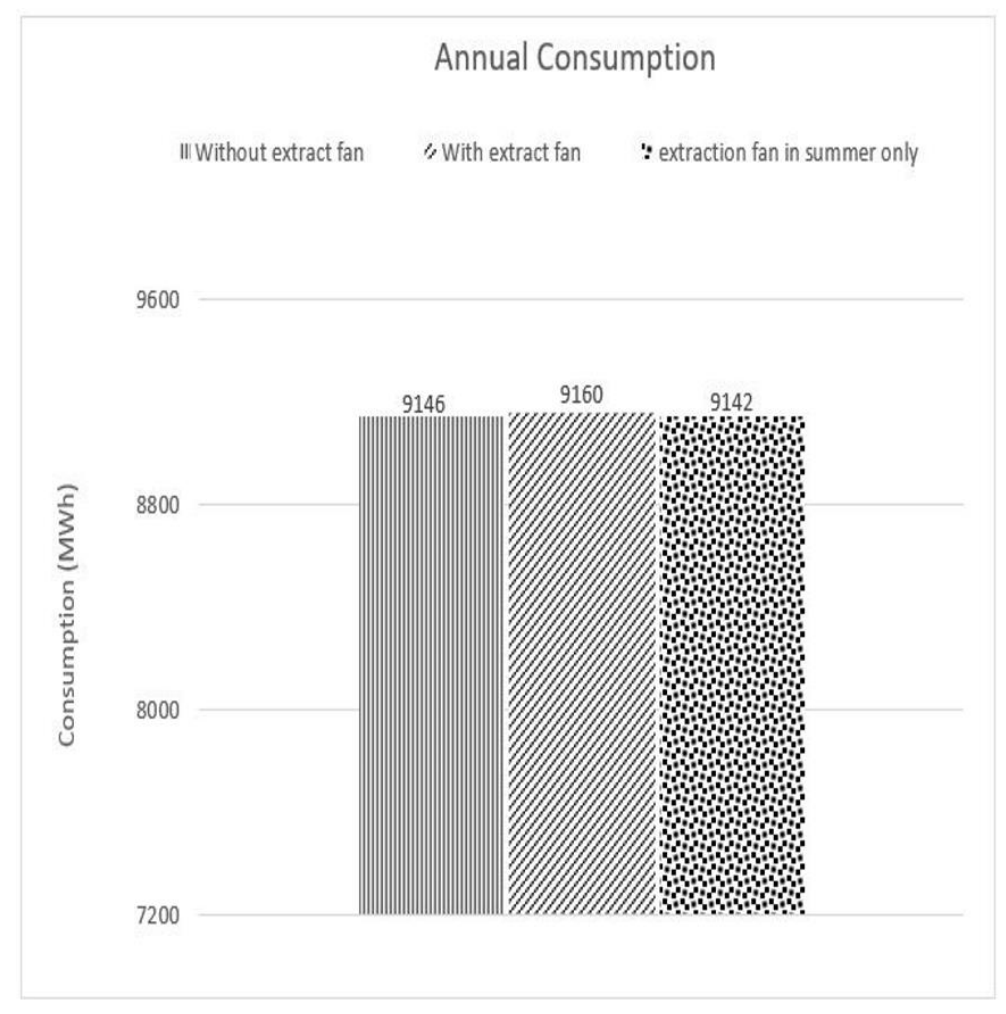

373 Figure 12: Annual overall energy consumption result (without extract fan vs. with extract fan vs 374 extract fan in operation in summer only) 


\section{$375 \quad 5.0 \quad$ Conclusion}

376 The case study investigated the impact of extract fans installed in the DSF cavity adjoining a large

377 central atrium to the east and west on the thermal performance of the atrium and consequently, the

378 overall energy performance of the hotel building. The case study building is an existing UK hotel

379 building (Hilton London Heathrow Airport) and the simulation was conducted using a building

380 energy simulation software. The software's energy estimate and thermal performance results were

381 validated with actual building consumption data before simulation and evaluation of the effect of

382 the installed façade extract fans on the energy performance of the case study building.

383 The case study results demonstrated that the resultant temperature of the façade cavity adjoining

384 the central atrium is substantially high. Temperature difference between the DSF cavity and the 385 atrium space of up to $11^{\circ} \mathrm{C}$ is observed in summer times and similarly, temperature difference of 386 up $-12^{\circ} \mathrm{C}$ is observed during the winter. This significant temperature difference between the façade 387 cavity and the atrium space and poses the risk of overheating and occupant discomfort especially 388 at during the summer.

389 The result of the model simulation incorporating extract fans in the façade cavity indicates that the 390 resultant temperature difference between the DSF façade cavity and the central atrium reduces 391 significantly relative to the model without extraction fans. This reduced temperature difference 392 results in improved internal temperature of the atrium space, marginally reducing the cooling 393 demand during the summer but also slightly increasing the winter heating requirement. The result 394 of the overall energy consumption shows that there is a marginal increase of $0.2 \%$ in the annual 395 energy consumption when the extraction fans are in operation throughout the year. 
396 However, the annual energy consumption result of the simulation with the extract fans operating 397 from May to September and off from October to April demonstrates that the $0.2 \%$ marginal energy 398 consumption increase is neutralized. Therefore, to improve the internal condition of the atrium 399 space without an increase in overall energy consumption, the optimum schedule of the extraction 400 fan is during the cooling dominant period from May to September.

401 
402

403

404

405

406

407

408

409

410

411

412

413

414

415

416

417

418

419

420

421

422

423

424

425

426

427

\section{Reference}

Abdullah, A.H. (2007) A Study on Thermal Environmental Performance in Atria in the Tropics with Special Reference to Malaysia. PhD thesis. Heriot-Watt University.

Aldawoud, A. \& Clark, R. (2008) Comparative analysis of energy performance between courtyard and atrium in buildings. Energy and Buildings, 40(3), pp.209-214.

Amoako-Attah, J. and B-Jahromi A. (2016) Impact of conservatory as a passive solar design of UK dwellings. Proceedings of the Institution of Civil Engineers - Engineering Sustainability 169(5): 198-213, http://dx.doi.org/10.1680/jensu.14.00040.

Ander, G.D. (2014) Windows and Glazing. Available at: https://www.wbdg.org/resources/windows.php (Accessed: 5 November 2016).

Building Regulations \&c. (Amendment) Regulations 2013 (SI 2013/0181). Available at: http://www.legislation.gov.uk/uksi/2013/181/regulation/1/made (Accessed 5 November 2016).

Cetiner, I. and Özkan, E. (2005) 'An approach for the evaluation of energy and cost efficiency of glass façades', Energy and Buildings, 37(6), pp. 673-684. doi: 10.1016/j.enbuild.2004.10.007.

Chou, S.K., Chua, K.J. \& Ho, J.C. (2009) A study on the effects of double skin façades on the energy management in buildings. Energy Conversion and Management, 50(9), pp.2275-2281. Available at: http://dx.doi.org/10.1016/j.enconman.2009.05.003.

CIBSE (2017) CIBSE Weather Data sets Available at: http://www.cibse.org/knowledge/cibse weather-data-sets (Accessed: 17 July 2017)

CIBSE (2009a) Use of climate change scenarios for building simulation: the CIBSE future weather years. CIBSE TM48. London: Chartered Institution of Building Services Engineers.

CIBSE (2009b) Energy efficiency in commercial kitchens CIBSE TM50. London: Chartered Institution of Building Services Engineers.

Crawley, D.B., Hand, J.W., Kummert, M., Griffith, B.T. (2008) Contrasting the capabilities of building energy performance simulation programs. Building and Environment, 43(4), pp.661 673. 
Eames, M.E. (2016). An Update of the UK's Design Summer Years: Probabilistic Design Summer Years for Enhanced Overheating Risk Analysis in Building Design. Journal of Building services engineering research and technology (Accepted)

EDSL TAS (2015). [online] Available at http://www.edsl.net/main/Software/Designer/NVandPD.aspx. [Accessed 2 July 2015].

Fallahi, A., Haghighat, F. and Elsadi, H. (2010) 'Energy performance assessment of double-skin facade with thermal mass', Energy and Buildings. Elsevier B.V., 42(9), pp. 1499-1509. doi:10.1016/j.enbuild.2010.03.020.

Gelesz, A. and Reith, A. (2015) 'Climate-based performance evaluation of double skin facades by building energy modelling in Central Europe', Energy Procedia 78. Elsevier B.V., 78, pp. 555560. doi: 10.1016/j.egypro.2015.11.735. Torino, Italy, 14 to 2 June 2015

Ghaffarianhoseini, A., Berardi, U., Tookey, J., Li, D. H. W. and Kariminia, S. (2016) 'Exploring the advantages and challenges of double-skin façades (DSFs)', Renewable and Sustainable Energy Reviews. Elsevier, 60, pp. 1052-1065. doi: 10.1016/j.rser.2016.01.130.

Gratia, E. and De Herde, A. (2004b) 'Natural cooling strategies efficiency in an office building with a double-skin façade', Energy and Buildings, 36(11), pp. 1139-1152. doi:10.1016/j.enbuild.2004.05.004.

Gratia, E. and De Herde, A. (2004a) 'Optimal operation of a south double-skin facade', Energy and Buildings, 36(1), pp. 41-60. doi: 10.1016/j.enbuild.2003.06.001.

Hee, W. J., Alghoul, M. A., Bakhtyar, B., Elayeb, O., Shameri, M. A., Alrubaih, M. S. and Sopian, K. (2015) 'The role of window glazing on daylighting and energy saving in buildings', Renewableand Sustainable Energy Reviews. Elsevier, 42, pp. 323-343. doi: 10.1016/j.rser.2014.09.020.

Hien, W. N., Liping, W., Chandra, A. N., Pandey, A. R. and Xiaolin, W. (2005) 'Effects of double glazed facade on energy consumption, thermal comfort and condensation for a typical office building in Singapore', Energy and Buildings, 37(6), pp. 563-572. doi: 10.1016/j.enbuild.2004.08.004.

Holmes, M.J. \& Hacker, J.N. (2007) Climate change, thermal comfort and energy: Meeting the design challenges of the 21st century. Energy and Buildings, 39(7), pp.802-814. 
Høseggen, R., Wachenfeldt, B.J. \& Hanssen, S.O. (2008) Building simulation as an assisting tool in decision making. Case study: With or without a double-skin façade? Energy and Buildings, 40(5), pp.821-827.

Jaberansari, M. \& Elkadi, H. (2016) 'Influence of different atria types on energy efficiency and thermal comfort of square plan high - rise buildings in semi - arid climate', International conference on Energy, Environment and Economics. August 16-18.

Kaluarachchi, Y., Jones K., James P., Jentsch M., Baha A. S., Clements-Croome D., and Gann D. (2005) 'Building façades: sustainability, maintenance and refurbishment.', Proceedings of the Institution of Civil Engineers - Engineering Sustainability, 158(2), pp. 89-95. doi: 10.1680/ensu.158.2.89.67119.

Kim, G., Schaefer, L. and Kim, J. T. (2013) 'Development of a Double-Skin Façade for Sustainable Renovation of Old Residential Buildings', Indoor and Built Environment, 22(1), pp. 180-190. doi: 10.1177/1420326X12469533.

Mylona Anastasia (2017) Revision of Design Summer years and Test Reference Years Available at: $\quad$ http://www.cibse.org/getmedia/cc70f2d9-8ef8-42cb-83ce-2316546f0aa0/Introduction-toCIBSE-Weather-Data-Files.pdf.aspx (Accessed: 17 July 2017)

Parra, J., Guardo, A., Egusquiza, E. and Alavedra, P. (2015) 'Thermal Performance of Ventilated Double Skin Façades with Venetian Blinds', Energies, 8(6), pp. 4882-4898. doi: 10.3390/en8064882.

Pasut, W. and De Carli, M. (2012) 'Evaluation of various CFD modelling strategies in predicting airflow and temperature in a naturally ventilated double skin facade', Applied Thermal Engineering. Elsevier Ltd, 37, pp. 267-274. doi: 10.1016/j.applthermaleng.2011.11.028.

Poirazis, H. (2004) Double Skin Façades for Office Buildings Literature Review. Lund University. Rotimi, A., Bahadori-Jahromi, A., Mylona, A., Godfrey, P. and Cook, D., 2017. Estimation and Validation of Energy Consumption in UK Existing Hotel Building Using Dynamic Simulation Software. Sustainability, [online] 9(8), p.1391. Available at: http://dx.doi.org/10.3390/su9081391

Virk, D. \& Eames M. (2016) CIBSE Weather Files 2016 release: Technical Briefing and Testing. Available at: http://www.cibse.org/getmedia/ce7a77e8-3f98-4b97-9dbc- 
$486 \quad$ 7baf0062f6c6/WeatherData_TechnicalBriefingandTesting_Final.pdf.aspx (Accessed: 17 July

$487 \quad 17,2017)$

488 Yuji-Suk, KimJin-Hee, KimSang-Myung, and KimJun-Tae. (2017) 'Thermal and energy

489 performance of a building with PV-applied double-skin façade'. Proceedings of the Institution

490 of Civil Engineers - Engineering Sustainability 0 0:0, 1-9.

491

492 